\title{
Deteksi Gerak Pada Citra Objek Video Surveillance Dengan Menggunakan Metode Spektral Residual
}

\author{
Lailia Rahmawati ${ }^{1}$, Hendro Nugroho ${ }^{2}$ \\ ${ }^{1}$ Jurusan Teknik Informatika, Universitas Darul 'Ulum Jombang \\ ${ }^{2}$ Jurusan Teknik Informatika Fakultas Teknologi Informasi, ITATSEmail: \\ lailiarahmawati88@gmail.com, ${ }^{2}$ dosh3ndro@itats.ac.id
}

\begin{abstract}
Video Surveilance is application that is often used in security system. The application of motion detection techniques to video surveillance is one of the most commonly used methods. The method of searcing motion objects in visual video using the Residual Spectral method. The stepstep in motion detection research is video input with size 176x144 pixels, segmentation process using Otsu Threshold method, Saliency Detection process using Residual Spectrum method, Tracking process to generate output Result motion detection result. Data for testing of 30 video data and a success rate of $90 \%$.
\end{abstract}

Keywords: Motion Detection, Video Surveilance, Residual Spectrum, Otsu Thershold

\begin{abstract}
Abstrak. Video Surveillance adalah salah satu aplikasi yang sering dimanfaatkan pada system keamanan. Penerapan teknik deteksi gerak (Motion Detection) pada video surveillance merupakan salah satu metode yang sering digunakan. Metode pencarian objek gerak pada visual video dengan menggunakan metode Spektral Residual. Langkap-langkah dalam penelitian deteksi gerak adalah input video dengan ukuran 176x144 piksel, proses segmentasi dengan menggunakan metode Threshold Otsu, Proses Saliency Detection yang menggunakan metode Spektrum Residu, Proses Tracking untuk menghasilkan hasil Output Objek deteksi gerak. Data untuk uji coba sejumlah 30 data video dan tingkat keberhasilannya sebesar $90 \%$.
\end{abstract}

Kata Kunci: Deteksi Gerak, Video Surveilance ,Spektral Residual, Thershold Otsu

\section{Pendahuluan}

\subsection{Latar Belakang}

Kebutuhan hidup manusia pada jaman sekarang adalah kebutuhan adanya rasa aman pada lingkungan. Oleh karena itu bidang teknologi multimedia dituntut untuk bisa menghasilkan hal-hal yang inovasi. Pemanfaatan teknologi multimedia ini telah banyak diterapkan pada berbagai bidang, salah satunya adalah pada sistem keamanan. Video Surveillance adalah salah satu aplikasi yang sering dimanfaatkan pada sistem keamanan. Video Surveillance pun harus dilengkapi dengan fasilitas pemantauan jarak jauh. Penerapan teknik deteksi gerak (Motion Detection) pada video surveillance merupakan salah satu metode yang sering digunakan.

Pada penelitian ini akan dilakukan penganalisaan dan pemodelan objek untuk menganalisa suatu gerakan pada video Surveillance. Dengan menggunakan metode Spektral Residual dapat membantu mendeteksi objek yang bergerak. Data yang dikumpulkan untuk penelitian berupa video yang diambil dari berbagai tempat seperti di jalan, halaman, di dalam mall dengan melakukan perekaman video pada objek manusia maupun kendaraan.

\section{Tinjauan Pustaka}

\subsection{Spectral Residual}

Model Spectral Residual tidak tergantung pada fitur, kategori, atau bentuk lain dari pengetahuan sebelumnya dari objek (Xiaodi Hou). Untuk deteksi Saliency secara visual untuk menganalisa dengan log-spektrum dari suatu gambar masukan, kita mengeksrak spectral residual dari suatu gambar dalam domain spectral, dan mengusulkan meted cepat untuk membangun saliency map sesuai didomain spasial (Ulrich Engelki).

Di mana banyak mekanisme pemrosesan visual yang dapat menghilangkan redudansi pada input sensorik. Prinsip dasar dalam sistem visual untuk menekan respon yang sering terjadi pada fitur, sementara pada saat yang sama. Waktu terus peka terhadap fitur yang menyimpang. Oleh karena itu, hanya sinyal tak terduga dapat disampaikan untuk tahap pengolahan selanjutnya. 


\section{Representasi Log spektrum}

Log spektrum diperoleh dari $(L(f)=\log A(f) . A(f)$ adalah amplitudo dari rata-rata Fourier spektrum. Mengingat gambar input, log spectrum $(L(f)$ dihitung dari gambar sampel dengan tinggi (atau lebar) sama dengan 64 px. Pemilihan ukuran masukan terkait dengan skala visual. Jika informasi yang terkandung dalam $(L(f)$ yang diperoleh sebelumnya, informasi yang diperlukan untuk diproses adalah:

$$
H(R(f))=H(L(f) A(f))
$$

Dimana $A(f)$ menunjukkan bentuk umum spektrum log, yang diberikan sebagai informasi awal. $R(f)$ menunjukkan statistik singularitas yang khusus untuk gambar input. Dalam penelitian ini, kita mendefinisikan $R(f)$ sebagai sisa spektral dari suatu citra.

\subsection{Operasi Markovian}

Manfaat Operasi Markovian adalah untuk memodelkan setiap gerakan agar dapat diamati dan lebih informatif maka digunakan pendekatan markovian yaitu dengan menggunakan rantai markov yang dikombinasikan dengan entropy (Nick Darusman).

\subsection{Informasi Saliency}

Model saliency pengetahuan menggunakan metode saliency kuantifikasi pertama yang disebut sebagai model M1. Metode ini memperhitungkan, bahwa saliency dalam wilayah distorsi bervariasi antara video yang berbeda. Untuk alasan ini, saliency di daerah terdistorsi diukur menggunakan saliency maps yang dibuat dari pola tatapan. Nilai rata-rata saliency kemudian dihitung atas seluruh wilayah distorsi dibawah ini (Ulrich Engelke):

$$
S_{1}=\frac{1}{\left(\lim _{b}-\lim t\right)\left(\lim _{r}-\lim l\right.} \sum_{m=\operatorname{limb}}^{\lim r} \sum_{m=\lim r}^{\operatorname{limr}} S(m, n)
$$

Dimana limb, limt, liml, dan limr, masing - masing, menyatakan batas wilayah distorsi pada bagian bawah, atas, kiri, dan benar, sementara menghitung rata-rata atas semua frame terdegradasi.

\section{Metode Penelitian}

Blok Diagram Analisa Sistem Pemodelan Saliency Berdasarkan Penglihatan, yang dimulai dari tahap pemodelan lingkungan background, tahap camera, tahap ekstraksi, tahap aktivasi, tahap normalisasi / kombinasi, tahap tracking. Untuk Pemodelan saliency berdasarkan penglihatan dengan menggunakan normalisasi / kombinasi dapat dilihat pada gambar 1.

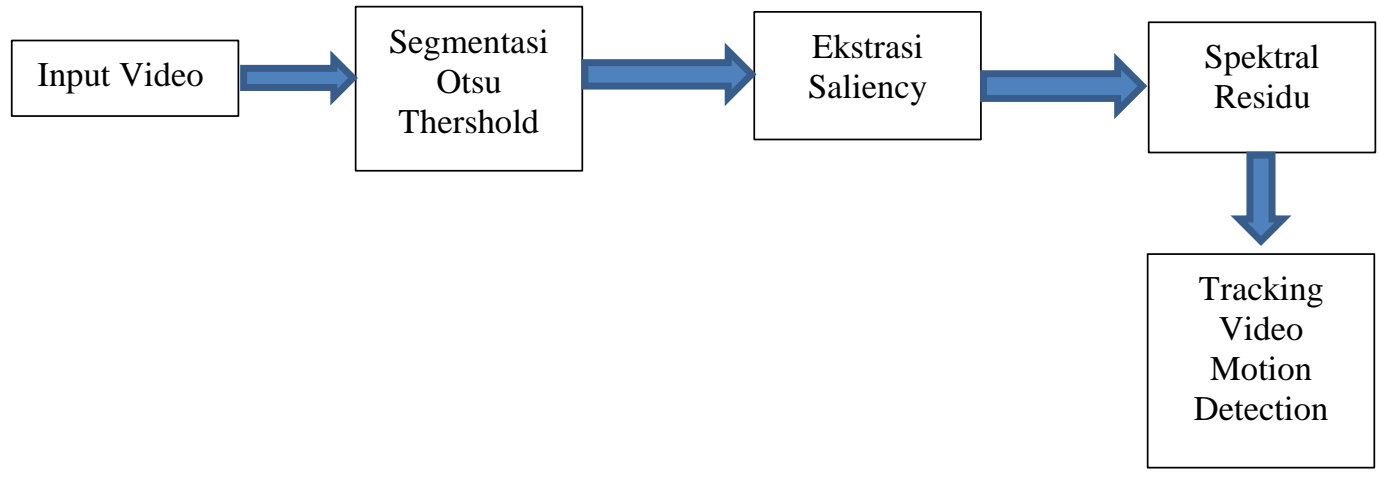

Gambar 1. Blok Diagram Analisa Motion Detection (Deteksi Gerak) 


\subsection{Data yang Digunakan}

Data video diolah dalam program tidak secara langsung tapi data video diambil dengan cara offline. Setelah melakukan perekaman, video disimpan lalu dipanggil open video dalam program deteksi objek. Pada gambar 2 tersebut menunjukkan data pada video V1.

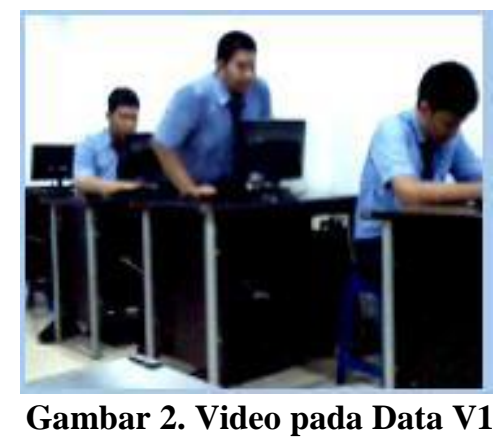

\subsection{Akuisisi Citra}

Didalam akuisisi citra dibutuhkan suatu alat pengambilan citra dengan cara merekam video. Alat yang digunakan untuk penggambilan citra dengan menggunakan Webcam Vimicro USB 2.0 UVC Camera VCO332, dengan ukuran citra objek $176 \times 144$ pixel dalam format file AVI. Pengambilan video pada waktu pagi pada jam 9.00 WIB sampai dengan 12.00 WIB. Tempat pengambilan video data tersebut dilakukan diluar ruangan dengan pencahayaan agak redup serta didalam ruangan kelas dan rumah. Jarak pengambilan video tersebut kurang lebih $3 \mathrm{~m}$ sampai dengan 5 meter. Untuk video data bisa dilihat pada Gambar 2

\subsection{Segmentation Threshold Otsu}

Tujuan dari metode otsu adalah membagi histogram citra gray level kedalam dua daerah yang berbeda secara otomatis tanpa membutuhkan bantuan user untuk memasukkan nilai amabang (threshold). Pendekatan yang dilakukan oleh metode otsu adalah dengan melakukan analisis diskriminan yaitu menentukan suatu variable yang dapat membedakan antara dua atau lebih kelompok yang muncul secara alami. Analisis deskriminasi akan memaksimumkan variable tersebut agar dapat membagi objek latar depan (foreground) dan latar belakang (background).

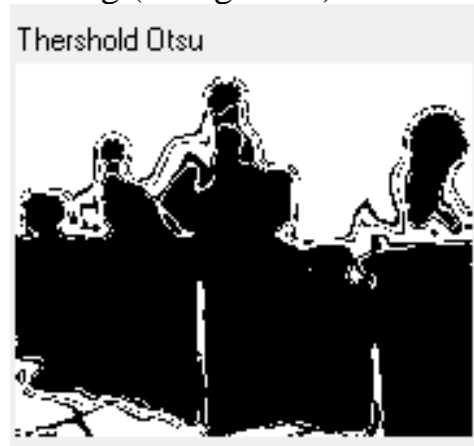

\section{Gambar 3. Hasil Proses Thershold Otsu}

\subsection{Sepktral Residual}

Metode Spektral Residual adalah sebuah metode deteksi saliency gerakan global berdasarkan analisis spektral yang bertujuan untuk menemukan dan melokalisasikan daerah yang menarik, dimana ada arus yang menonjol. Yang dimana spektral residual tersebut didapat dari selisih antara Spektrum Log atau Log Spektrum dengan Spektrum Log Halus atau Smooth Log Spektrum. Untuk ilustrasi Spektrum Log, Spektrum Log Halus dan Spektral Residual bisa dilihat pada gambar 4 
Dalam proses Spektral residual ini tidak menggunakan tahap Optical Flow Field. Tahap selanjutnya adalah menghitung Spektrum Log. Untuk rumus mencari Spektrum Log dapat dilihat pada persamaan 1.

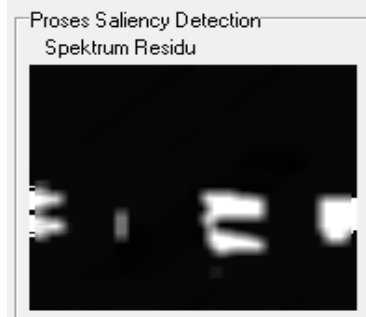

Gambar 4 (a)

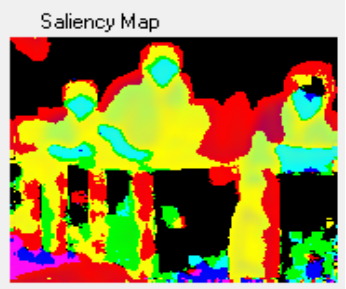

Gambar 4 (b)

Gambar 4 (a) adalah Gambar Hasil Spektral Residual pada Video V1; Gambar 4 (b) adalah Gambar Hasil Saliency Warna pada Video V2.

\subsection{Hasil Sepktral Residual}

Hasil dari penghitungan ekstraski menggunkakan Sepktral Residual menghasilkan nilai-nilai citra hasil fourier (table 1), nilai fourier Magnitude (table 2), nilai fourier Phases (table 3) dan hasil nilai log spectrum (table 4)

Tabel 1 Citra Hasil Fourier

\begin{tabular}{ccc}
\hline $\mathbf{F}(\mathbf{x})$ Real & $\mathbf{F}(\mathbf{u})$ Real & Imajiner \\
\hline 114 & 124,3333 & 0 \\
\hline 111 & 8,666667 & 37 \\
\hline 118 & $-28,3333$ & 0
\end{tabular}

Tabel 2 Menghitung Fourier Magnitude

\begin{tabular}{cccc}
\hline \multirow{2}{*}{$(\mathbf{x})$ Real } & \multicolumn{2}{c}{$\mathbf{F}(\mathbf{u})$} & \multirow{2}{*}{ Fourier Magnitude A(f) } \\
\cline { 2 - 3 } & Real & Imajiner & \\
\hline 114 & 124,3333 & 0 & 124 \\
\hline 111 & 8,666667 & 37 & 38 \\
\hline 118 & $-28,3333$ & 0 & 28 \\
\hline
\end{tabular}

Fourier Phases dengan rumus $P(f)=\mathfrak{H}(\mathfrak{S}[I(x)]$

$$
\text { Rumus menghitung Phase : } \quad \operatorname{Arg}\{F(k)\}=\frac{\operatorname{Im}\{F(k)\}}{\operatorname{Re}\{F(k)\}}
$$

Tabel 3 adalah tabel hasil perhitungan Fourier Phases.

Tabel 3 Hitungan Fourier Phases

\begin{tabular}{cccc}
\hline $\mathbf{F}(\mathbf{x})$ & \multicolumn{2}{c}{$\mathbf{F}(\mathbf{u})$} & \multirow{2}{*}{ Fourier Phase $\mathbf{P}(\mathbf{f})$} \\
\cline { 2 - 3 } Real & Real & Imajiner & 0 \\
\hline 114 & 124,3333 & 0 & 4 \\
\hline 111 & 8,666667 & 37 & 0 \\
\hline 118 & $-28,3333$ & 0 & \\
\hline
\end{tabular}

Tabel 4 adalah hasil perhitungan Rumus Log Spektrum. 
Tabel 4 Hasil Hitungan Log Spektrum

\begin{tabular}{|c|c|c|c|c|}
\hline \multirow{2}{*}{$\begin{array}{l}\mathbf{F}(\mathbf{x}) \\
\text { Real }\end{array}$} & \multicolumn{2}{|c|}{$\mathbf{F}(\mathbf{u})$} & \multirow{2}{*}{$\begin{array}{c}\text { Fourier Magnitude } \\
\mathbf{A}(\mathbf{f})\end{array}$} & \multirow{2}{*}{ Log Spektrum L(f) } \\
\hline & Real & Imajiner & & \\
\hline 114 & 124,3333 & 0 & 124 & 2 \\
\hline 111 & 8,666667 & 37 & 38 & 2 \\
\hline 118 & $-28,3333$ & 0 & 28 & 1 \\
\hline
\end{tabular}

\subsection{Hasil Tingkat Keberhasilan}

Dari 30 data yang tersedia, 27 data sesuai dalam pendeteksian. Terdapat 3 data yang tidak sesuai dalam pendeteksian.

Prosentasi Keberhasilan adalah

$$
=\frac{(30-3)}{30} \times 100 \%=\frac{27}{30} \times 100 \%=90 \%
$$

\section{Kesimpulan}

Berdasarkan penelitian yang telah dibuat beserta uji coba yang telah dilakukan, maka peneliti dapat menarik kesimpulan sebagai berikut

1. Deteksi Gerak dengan menggunakan metode spektral residual dapat mendeteksi sesuai sebanyak 27 data dari 30 data yang tersedia.

2. Proses smoothing dengan menggunakan metode low pass filter dengan nilai $7 \times 7$ piksel sangat membantu menghaluskan citra dari noise untuk hasil proses deteksi Gerak yang lebih baik. Tetapi low pass filter dengan nilai $3 \times 3$ lebih cepat dalam penganalisaannya.

3. Boxing ganda dapat terjadi disaat warna objek lain sama dengan warna objek yang terdeteksi.

4. Pencahayaan pada lokasi pengambilan data sangat berpengaruh pada hasil deteksi Gerak.

5. Banyak ragam bentuk dan warna backgroud dapat mempengaruhi dalam deteksi Gerak.

\section{Referensi}

Chen Change Loy, Tao Xiang, Shaogang Gong. Salient Motion Detction Crowded Scenes. School of EECS, Queen Mary University of London.

Mohammad Anvaripour, Ramin Shaghaghi Kandovan, Sima Soltanpour. Low Distance Airplanes Detection And Tracking Visually Using Spectral Residual And KLT Composition. Research Institute for ICT, ACECR, Tehran, Iran.

Nick Darusman, Wirawan. Analisa Dan Pemodelan Kerumunan Orang Pada Video Digital. Jurusan Teknik Elektro FTI - ITS.

Ulrich Engrlke, Marcus Barkowsky, Patrick Le Callet, and Hans-Jurgen Zepernick. Modelling Saliency Awareness For Objective Video Quality Assemenss. Blekinge Institute of Technologu, Ronneby, Sweden.

Xiaodi Hou and Liqing Zhang. Saliency Detection A Spectral Residual Approach. Department of Computer Science, Shanghai Jio Tong University, Dongchuan Road, Shanghai. 